walls, porticoes, halls and columns were thrown open to their fullest extent, the ore glittering on all sides with a ruddy glow and almost blinding the eyes with rays of golden colour, so that the guests now coming from Fahlun seemed to be, as it were, introduced into the presence of Venus herself, sitting as a bride or newly-wedded wife in her most splendid decorated bridal chamber, ready to receive and welcome them most joyfully".

The extraction of copper from its ores, mainly sulphide ores, containing iron, usually with some arsenic and antimony, was a long and laborious process. Briefly, it was as follows: First there was a calcination to drive off volatiles, wood fuel being used. This was followed by fusion and smelting, in which the fuel was crushed coal, the air being blown in from a blast pipe about three inches in diameter. In this way a copper 'stone' was produced and collected in the fore-hearth, which was tapped every two hours. This stone was of an intense blood-red colour and flowed very slowly. Then followed a second calcination which consisted of six successive treatments in a 'burning fire'. The gradual removal of the volatiles took place, with accordingly an enrichment of copper. This calcination lasted about five weeks. Then came a second smelting, which occupied a further week, in which further quantities of iron were slagged off, and the cupreous product was tapped from time to time. This was known as coarse or black copper. These furnaces were situated within a mile of the mine, and there were about a hundred and thirty of them. Next followed the refining of the coarse copper at Afwedstad in Sweden, and the final stage consisted in the smelting of this so that it could be beaten out into laminæ or plates. The total period required was between seven and eight weeks and the maximum annual production was about 2,000 tons, corresponding to a weekly output of not more than 40 tons. When it is considered that the daily production of a modern copper works is of the order of 300 tons of refined metal, it will be realized that considerable advances have been made in the smelting and refining of copper in the last two hundred years.

The British Non-Ferrous Metals Research Association is to be commended for its public spirit in rendering available a treatise which gives so much information about the metallurgy of copper in the late seventeenth and early eighteenth centuries.

H. C. H. C.

\title{
Oceanography and the Fluctuations in the Abundance of Marine Animals*
}

\author{
By Dr. Stanley Kemp, F.R.S.
}

$I_{\mathrm{w}}^{\mathrm{T}}$ is interesting to note that the observations we have of salinity and temperature cannot be correlated with the biological data. For many years past, Dr. H. W. Harvey has followed the temperature and salinity changes at the western end of the Channel, and during the period since 1924 he has found that the most conspicuous movements were large incursions of low-salinity water in May 1928 and in March and April 1936, while in 1932,1933 and 1934 (especially in 1933) patches of water with unusually high salinity moved eastwards up the Channel. So far as can be seen, these movements show no correspondence with the marked biological changes which have occurred: it is in the phosphate data only that a correlation can be found.

In the year 1921 there was an exceptional influx of Atlantic water, which filled the Channel and flooded into the North Sea. Salinity and temperature were much above normal and numbers of unusual planktonic organisms of Atlantic origin were found in the North Sea. Recent experience

(Continued from p. 779.) at Plymouth might lead one to think that such an influx as this would bring benefit to the herring fisheries, but actually it was just the reverse, for at Plymouth and in the North Sea, at Lowestoft, Yarmouth, Grimsby and North Shields, the herring fishery was much below normal.

It thus appears that incursions of Atlantic water into the Channel may bring advantage to the biology of the area or may be detrimental, that no obvious connexion between the biological data and temperature and salinity is noticeable, and that so far as we can at present see, the only correlation that can be established is with phosphate. The explanation lies, I believe, in our very considerable ignorance of the constitution and origin of the water-masses which from time to time enter the Channel.

There is evidently more than one way in which an influx of Atlantic water may be advantageous. It may, in the first place, bring water with a high content of phosphate and other nutrient salts which will eventually yield an abundant plankton. Or, secondly, though deficient in phosphate, it 
may bring in large quantities of phytoplankton or zooplankton, the product of a former richness in phosphate. This plankton will-afford an immediate food-supply for larval fish and other animals, and when it dies down the phosphate will be regenerated and will serve for further plankton production in the future.

It is thus what we may call the biological condition of the water that is of importance, and this no doubt is to some extent determined by the season of the year. At times, in summer, the surface water may be largely devoid of both plankton and phosphate, and an influx of such water, even though its high salinity may indicate an oceanic origin, will bring no improvement to biological conditions and may indeed be harmful. In winter, when the thermocline has broken down and surface phosphate has been renewed by convection and by stormy weather, an influx may prove of advantage. But it is perhaps more probable that upwelled water, rich in the nutrient salts which are always to be found in the lower layers of the ocean, is the potent source of surface enrichment, and of the conditions in which such upwelling occurs we are very largely ignorant. We lack the necessary data and can merely speculate on what may be happening from analogy with what is known in other areas.

I have dwelt at some length on these events in the Plymouth area because they afford a good example of a long-period fluctuation and illustrate the way in which observations drawn from widely different lines of inquiry are linked together. From other sources also there is good evidence of long-period fluctuations in fisheries, and though the hydrographical changes to which they may ultimately be traced are not, as it appears, the same as in the Channel, they show that major alterations extending over a long term of years are by no means unusual.

In 1925 the Norwegians discovered great numbers of cod on the banks surrounding Bear Island, and ever since that year, except in 1929 when ice interfered with the operations, the fishery has been maintained, many trawlers visiting the banks annually to take toll of their wealth. Iverson, from whose paper my information on this fishery is derived, states that there was a former occasion when cod were plentiful in this area. That was from 1873 until 1882 . Between 1883 and the time when the present fishery began, the grounds were examined on a number of occasions, but very few cod were found and the results were unprofitable. It was so in 1924, the year which preceded the present period of abundance.

Another instance is afforded by the cod fishery in West Greenland. At certain times large concentrations of cod appear on this coast and spread as far north as Disko Bay, affording a profitable fishery ; but after a term of years their numbers suddenly decline and a protracted period of scarcity follows. In 1917 cod were found in West Greenland in great abundance and the fishery on this coast has been maintained up to the present day. Prior to that, as Jensen and Hansen have shown, the grounds were tested on a number of occasions without finding stocks of cod in marketable quantity; but early records indicate that there were at least two periods, in 1820 and in $1845-49$, when cod were present in great numbers.

To these two instances of large-scale changes in the fish population in northern waters many others could be added, and all are apparently due to the same cause - to the fact that in recent years the entire area from Greenland to Bear Island has become appreciably warmer. Berg has collected much information on the effects of this rise in temperature, Saemundsson has given an interesting account of the alterations which have occurred in the fauna of Iceland, while Stephen has shown that marked changes have also taken place in the British marine fauna. It is clear that an increased sea-temperature, probably of the order of $1 \cdot 0-2 \cdot 0^{\circ} \mathrm{C}$., has allowed various species of fish to extend beyond the normal limits of their distribution, with the result that it has been possible to establish productive fisheries in areas which formerly would not have yielded an adequate return. It is evident, I believe, that at some future date conditions will revert to normal, and that a time will come when these lucrative fisheries will cease to exist.

A distinction-which I believe to be a real onecan therefore be drawn between two kinds of fluctuations, both of which have a pronounced effect on the marine fauna. Normal annual fluctuations are a constant feature. They form the basis of fishery prediction, and our information, such as it is, is that their incidence is restricted: a fishery for a certain species in a particular place will be affected, while other species in the same place, or the same species in another place will be unaffected. It is to be assumed that the causes of such annual fluctuations, though of these we know but little, are also restricted both in space and in time.

In contrast are what I have called long-period fluctuations, which extend over a term of years and involve much larger areas. Such fluctuations as these are due to a widespread change in one or more of the hydrographic factors in the environment, and large numbers of species, if not all, are affected simultaneously or within a short period. Long-period fluctuations may mask the effects of the annual fluctuations and at times they will render fishery prediction unreliable. 


\section{Research IN the Atlantic}

Long-period fluctuations may be brought about in entirely different ways. In the Channel, as it appears, the change can be traced to a deficiency in phosphate, while in more northerly areas it is due to an increase in sea temperature. But, though there is this wide difference, the two sets of circumstances have this in common, that they originate in the open Atlantic, at the edge of the continental slope or farther to the west. It is here, in oceanic waters, that the causes of these large alterations in European fisheries must be sought.

It might be thought that a full investigation of the Atlantic drift, to which we owe so many advantages, would long since have been undertaken. Yet, to the present day, there are many problems which remain unsolved and, as Dr. Iselin has recently shown, three mutually conflicting theories are extant regarding the circulation of water in the North Atlantic. Fortunately there are signs that a period will be set to our ignorance. On the American side of the Atlantic, the Woods Hole Oceanographic Institution and the Bermuda Biological Station are collaborating in a study of the Gulf Stream and of the effect of wind velocity and direction on the strength of a current. Data recently obtained by the Woods Hole Institution show that the transport of water in the Gulf Stream has varied by as much as 20 per cent in fourteen months, and it may well be that this figure is below the normal range of variation. When the observations over the five-year period which is contemplated have been carried out, we may hope to know far more than we do at present of the Gulf Stream and its effects on circulation in the North Atlantic.

During the present year, a German research ship is making a prolonged investigation of the hydrography of the North Atlantic, and only two months ago research ships from Denmark, Norway and Scotland were co-operating with her in studying extensive areas from the Azores to Iceland.

From such combined attack we shall learn much, and there is every reason to believe that the main features of the circulation in the North Atlantic will shortly be understood. But the work in the eastern Atlantic is only an isolated set of observations, most valuable as a contribution to our knowledge of the general conditions, but affording little help in solving the problem of long-period faunistic fluctuations of which I have spoken. It is the deviations from the normal which are of paramount importance to the biologist, and it is only by repeated observations made over a series of years that they can be detected. I believe that the need for systematic oceanographic work in the eastern Atlantic will be more and more acutely felt as time goes on, and I feel convinced that it is the only way in which we can ever reach an understanding of the reasons for the large fluctuations in our fisheries.

\section{Fisheries ResEARCH IN THE BrITISH EMPIRE}

There is an urgent need throughout a very large part of the British Empire for greater activity in the scientific administration of the fisheries, for to me at least it is apparent that the lessons which long years of experience have taught us in Great Britain are not generally understood elsewhere.

The plain fact is that in the Empire as a whole we are deplorably deficient in fisheries administration. To this broad statement there are of course some exceptions. By reason of its situation in Europe, the Irish Free State is obviously one of them, and it has taken its full share in the progress that has been made during the present century. Another exception is Canada, where a vigorous fisheries service, with a competent scientific staff, has been at work for many years. Newfoundland, a country to which fisheries are of predominant importance, not long since suffered a shattering blow in the loss of the whole of its laboratory buildings by fire, but it will recover from this disaster and we may hope that the work which had such a brilliantly successful beginning will shortly be resumed. Australia has now made a fresh start after the tragic loss of the Endeavour, and has at last taken the wise step of founding a Commonwealth fishery department. These are the high lights, and there are one or two colonies, such as the Straits Settlements and Ceylon, which give relief to what is otherwise a very sombre picture.

In South Africa, with its astonishingly rich fish. ing grounds and vast length of coast-line, the fishery staff is utterly inadequate, and in India, where fisheries research has immense possibilities, there is apparently little hope that proper action will be taken. In India fisheries are what is known as a transferred subject: that is to say, they have been handed over by the central Government to the provincial administrations. The result is that some provinces may have a scientific staff of one, others have none at all, while Madras, which is much the most enterprising and publishes a fisheries bulletin, has three. In such conditions fishery work on any adequate scale is clearly out of the question, and it is not possible even to begin the acquisition of the fundamental knowledge that is essential to future progress.

In almost every problem which touches marine biology it is essential to possess a background 
of knowledge which can only be acquired by long years of patient study. If there is one lesson to be learnt from the history of fisheries research-one that cannot be too heavily stressedit is that the opportunity of dealing effectively with a fishery problem will generally be lost unless this basic knowledge has been obtained in advance and is ready for application. Even in our home waters, which have been examined so long and so closely, our information is not within sight of being complete : in almost every branch of fisheries work there are new fields to be explored, new methods to be tried and many large gaps in the knowledge we possess. But it may at least be said that we have made a beginning. In many other parts of the world not even a beginning has yet been made ; ignorance is profound and there is no background of knowledge which can be utilized.

It is surely time that the importance of such knowledge was recognized and that early steps were taken to lay the foundations of fishery science throughout the Empire.

\title{
International Standard of Musical Pitch
}

\author{
By Dr. G. W. C. Kaye, O.B.E.
}

THE problem of the international standard.

1 ization of musical pitch has recently assumed a new prominence in view of the increasing exchange of concert and similar programmes by the various broadcasting organizations in different countries. The general question has come up from time to time in the past, though it cannot be said that any substantial measure of unification has ever resulted internationally.

The history of musical pitch is one of many 'standards', mainly evolved by some body of standing, which at the time was able to impose its will to a greater or less extent on current practice. In some countries, indeed, the choice of pitch was, and still is, enforced by legal decree. It has long been customary to express musical pitch in terms of the frequency of the note $A$ in the treble clef; and this convention will be observed in what follows.

Ellis (J. Roy. Soc. Arts, 1880) gives us a good notion of the state of affairs which prevailed in the early history of musical pitch. It appears that from the fourteenth to the seventeenth century, the note A wandered haphazardly over a range of nearly 200 cycles per second ( 374 to 567 ). In the eighteenth century, the upper limit came down by more than 100, the spread of pitch being from 377 to about 423. During the nineteenth century the range was from about 424 to 494 , a progressive rise being evident up to about 1887, reflecting no doubt, as always, a striving for increased brilliancy.

In Great Britain, the London Philharmonic Orchestra was the premier orchestra for many years, and the philharmonic pitch was followed by most other orchestras, being first based in $\mathbf{1 8 2 6}$ on a value of $\mathbf{4 3 3}$ for $A$, and afterwards (nineteen years later) on 455 . A conference of physicists at Stuttgart in 1834 adopted 440 , while a similar conference of musicians and physicists appointed by the French Government in 1859, established the 'Diapason Normal', which was based on a figure of 435 (largely through the influence of Koenig), the associated temperature of the instruments being taken as $15^{\circ} \mathrm{C}$. $\left(59^{\circ} \mathrm{F}\right.$.). This pitch, which was legalized in France and had a fairly wide vogue in Europe, was adopted by the Boston Symphony Orchestra at its foundation in 1883, and was endorsed in 1885 by an international congress at Vienna. In 1896, the Philharmonic Society adopted 439 at $68^{\circ} \mathrm{F}$. (see Hipkins, NatUre, Aug. 31, 1899), while in 1899 an international discussion by the pianoforte trade, which revealed values of $A$ ranging from 435 to 442 , also resulted in the adoption of 439 at $20^{\circ} \mathrm{C}$. $\left(68^{\circ} \mathrm{F}\right.$.) by the participating makers, a decision which materially assisted in checking the general tendency of pitch to rise. Another significant step was the lowering in 1927 by the Army Council of the pitch of British Army bands from 455 to 439 at $68^{\circ} \mathrm{F}$.

In the United States, while musical pitch was the subject of many vagaries during the last century, a figure of $\mathbf{4 4 0}$ is now universal, having been adopted by the American Federation of Musicians in 1918, the Music Industries Chamber of Commerce in 1925, and the American Standards Association in 1936. It may be added that this value is in good accord with the usual British figure, as the temperature in American concert halls is said to be customarily of the order of $70^{\circ} \mathrm{F}$.

To come to more recent events, a conference was recently held at Broadcasting House under the auspices of the British Standards Institution, with Dr. G. W. C. Kaye in the chair. The conference was attended by representatives of some thirty musical and other organizations, including the Royal Academy of Music, the Royal College of Music, the Royal College of Organists, the Royal Military School of Music, the Musical Association, 